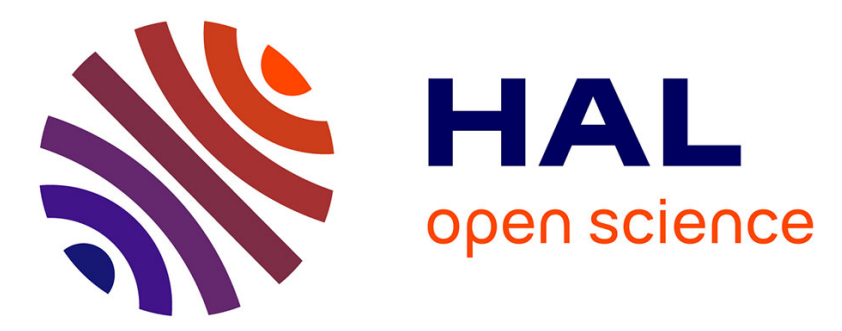

\title{
Harmonic phases of the nanoparticle magnetization: An intrinsic temperature probe
}

Eneko Garaio, Juan Mari Collantes, Jose Angel Garcia, Fernando Plazaola, Olivier Sandre

\section{- To cite this version:}

Eneko Garaio, Juan Mari Collantes, Jose Angel Garcia, Fernando Plazaola, Olivier Sandre. Harmonic phases of the nanoparticle magnetization: An intrinsic temperature probe. Applied Physics Letters, 2015, 107 (12), pp.Art Nb 123103. 10.1063/1.4931457 . hal-01383239

\section{HAL Id: hal-01383239 \\ https://hal.science/hal-01383239}

Submitted on 24 Oct 2018

HAL is a multi-disciplinary open access archive for the deposit and dissemination of scientific research documents, whether they are published or not. The documents may come from teaching and research institutions in France or abroad, or from public or private research centers.
L'archive ouverte pluridisciplinaire HAL, est destinée au dépôt et à la diffusion de documents scientifiques de niveau recherche, publiés ou non, émanant des établissements d'enseignement et de recherche français ou étrangers, des laboratoires publics ou privés. 
This document is the Accepted Manuscript version of a Published Work that appeared in final form in Appl. Phys. Lett. 107, 123103 (2015) @ AIP Publishing LLC (American Institute of Physics, USA) after peer review and technical editing by the publisher. To access the final edited and published work see $\mathrm{http} / / / \mathrm{dx}$.doi.org/10.1063/1.4931457

Harmonic phases of the nanoparticle magnetization: an intrinsic temperature probe Eneko Garaio, ${ }^{1, a)}$ Juan-Mari Collantes, ${ }^{1}$ Jose Angel Garcia, ${ }^{2,}{ }^{3}$ Fernando Plazaola, ${ }^{1}$ and Olivier Sandre ${ }^{4, b)}$

1) Elektrizitatea eta Elektronika Saila, UPV/EHU, 644.48080 Bilbao. Spain

2) Fisika Aplikatua II Saila, UPV/EHU, 644.48080 Bilbao. Spain

${ }^{3)}$ BC Materials (Basque Center for Materials, Application and Nanostructures) 48040 Leioa. Spain

4) Laboratoire de Chimie des Polymères Organiques, UMR 5629 CNRS/Université de Bordeaux, Bordeaux. France

(Dated: 8 September 2015)

Magnetic fluid hyperthermia is a promising cancer therapy in which magnetic nanoparticles act as heat sources activated by an external AC magnetic field. The nanoparticles, located near or inside the tumor, absorb energy from the magnetic field and then heat up the cancerous tissues. During the hyperthermia treatment, it is crucial to control the temperature of different tissues: too high temperature can cause undesired damage in healthy tissues through an uncontrolled necrosis. However, the current thermometry in magnetic hyperthermia presents some important technical problems. The widely used optical fiber thermometers only provide the temperature in a discrete set of spatial points. Moreover, surgery is required to locate these probes in the correct place. In this scope, we propose here a method to measure the temperature of a magnetic sample. The approach relies on the intrinsic properties of the magnetic nanoparticles because it is based on monitoring the thermal dependence of the high order harmonic phases of the nanoparticle dynamic magnetization. The method is non-invasive and it does not need any additional probe or sensor attached to the magnetic nanoparticles. Moreover, this method has the potential to be used together with the magnetic particle imaging technique to map the spatial distribution of the temperature.

\footnotetext{
a) eneko.garayo@ehu.eus

b) olivier.sandre@enscbp.fr
} 
This document is the Accepted Manuscript version of a Published Work that appeared in final form in Appl. Phys. Lett. 107, 123103 (2015) () AIP Publishing LLC (American Institute of Physics, USA) after peer review and technical editing by the publisher. To access the final edited and published work see http://dx.doi.org/10.1063/1.4931457

\section{INTRODUCTION}

Tumor destruction with magnetic nanoparticles (MNPs) under an applied human tolerable AC magnetic field is a promising cancer therapy called magnetic fluid hyperthermia $(\mathrm{MFH})$ or sometimes called magnetic hyperthermia ${ }^{1,2}$. The most common used heat-sources are superparamagnetic iron oxide nanoparticles. These nanoparticles are also used as contrast agents in magnetic resonance imaging $(\mathrm{MRI})^{3,4}$ and their spatial distribution can also be acquired by the magnetic particle imaging (MPI) technique ${ }^{5,6}$, especially for in-vivo diagnostics, where this information is key for a proper magnetic hyperthermia treatment.

On the one hand, the control and mapping of temperatures in the tumor and the surrounding tissues is crucial during any hyperthermia treatment. The desired therapeutic effect may not be achieved with a temperature increment lower than expected. On the contrary, an excessive temperature increment can produce undesired damage to healthy tissues or too many necrotic cells ${ }^{7}$. There exist only few systems to measure and control the temperature in hyperthermia treatment. The use of optical fiber thermometry in magnetic hyperthermia provides a good way to acquire in situ local temperature through the luminescence of a semiconducting crystal (e.g. GaAs). However, it only provides the temperature in a discrete set of spatial points and, in addition, the minimum size of the fiber tip is around $200 \mu \mathrm{m}$ (and it is very fragile and sensitive to mechanical stresses). Moreover, surgery is needed to place the tip in the desired place through a catheter, which may be extremely complicated. Therefore, alternative remote sensing methods are subject of investigation. Some of them are based on MRI techniques that exploit the change with temperature of proton density, of T1 (longitudinal) water proton relaxation times, of water molecular diffusion coefficient or of proton resonant frequency through a phase signal analysis ${ }^{8}$. Moreover, measurements of T1 relaxation times that are accurate enough to infer the temperature can be very time consuming and very sensitive to mechanical factors such as animal breathing. Another proposed method to control the temperature during magnetic hyperthermia treatment is the use of self-regulated magnetic nanoparticles as heat sources ${ }^{9,10}$. The use of a lanthanide complex absorbed on the nanoparticles for thermometry as molecular thermometric probe ${ }^{11}$, or the anchoring of a thermo-sensitive polymer at the surface or outer shell of the nanoparticles to modulate the MRI contrast ${ }^{12}$ are also subjects of investigation. For the same thermometry purpose but not necessitating a chemical modification of the MNPs, Weaver et al. ${ }^{13}$ proposed 
This document is the Accepted Manuscript version of a Published Work that appeared in final form in Appl. Phys. Lett. 107, 123103 (2015) () AIP Publishing LLC (American Institute of Physics, USA) after peer review and technical editing by the publisher. To access the final edited and published work see http://dx.doi.org/10.1063/1.4931457

a method based on the ratio of the $5^{\text {th }}$ and $3^{\text {rd }}$ harmonics of the magnetization generated by magnetic nanoparticles, varying the amplitude of the sinusoidal field at a fixed frequency of $1.47 \mathrm{kHz}$.

On the other hand, one of the most important parameters of magnetic nanoparticles design for magnetic fluid hyperthermia is their specific absorption rate $(S A R)$. Two different approaches are used for $S A R$ measurements. The most commonly used approach is the calorimetric method, consisting in measuring heating rates from the initial slope of temperature versus time ${ }^{14-16}$. However, there are many factors that affect the accuracy of these methods ${ }^{17,18}$. An alternative approach consists in the measurement of the dynamic magnetization versus applied magnetic field ${ }^{19,20}$. This method permits precise and quick $S A R$ measurements, allowing multi-parametric study for different frequencies, field intensities and as a function of temperature ${ }^{21,22}$. Using the fundamentals and advantages of this last technique, we propose here an accurate, simple and fast method for monitoring and controlling the temperature of magnetic nanoparticles during magnetic hyperthermia. The method does not need any additional probe or sensor attached to the magnetic nanoparticles. Fundamentally, it is based on the thermal dependence of the phase of the high order harmonics of the nanoparticles response to the magnetic field variation. Also, the method can be easily implemented to study the heat transfer between nanoparticles and the surrounding medium or other phenomena related to magnetic nanoparticles, for instance magnetic field induced drug-delivery.

Moreover, this method could be used together with the magnetic particle imaging technique to map the temperature. MPI measures the spatial distribution of the high order harmonics (see references ${ }^{5,6}$ ). In this case, the spatial distribution of the harmonic phases could be measured in order to map the temperature in the areas where the magnetic particles are placed.

\section{EXPERIMENTAL}

The magnetic iron oxide nanoparticles are identical to those used in a previous work on the comparison of $S A R$ measurement by calorimetry and by AC magnetometry ${ }^{23}$. Briefly, a water dispersed maghemite nanoparticle sample was prepared by the alkaline co-precipitation route. This method usually leads to well crystalline and magnetic iron oxide nanoparticles 
This document is the Accepted Manuscript version of a Published Work that appeared in final form in Appl. Phys. Lett. 107, 123103 (2015) () AIP Publishing LLC (American Institute of Physics, USA) after peer review and technical editing by the publisher. To access the final edited and published work see http://dx.doi.org/10.1063/1.4931457

but having a broad range of diameters. Therefore a size-grading process based on successive phase separation by an added electrolyte was applied ${ }^{24}$, in order to isolate a fraction with the largest diameters i.e. around 15-20 nm, still below the threshold size above which iron oxide MNPs have their magnetic moments blocked at ambient temperature ${ }^{25}$. This sample consists of water dispersion in acidic conditions $(\mathrm{pH} \approx 1.9)$ of maghemite nanoparticles. The iron oxide concentration was measured at $12 \mathrm{mg} \cdot \mathrm{mL}^{-1}$ from a UV-vis measurement compared to a calibration spectrum. The equivalent concentration of iron is $0.15 \mathrm{~mol} \cdot \mathrm{L}^{-1}$ and the solid volume fraction is $0.24 \%$.

The DC magnetization of the water dispersed nanoparticles was measured by vibrating sample magnetometry (VSM). Fitting the Langevin function to the experimental DC magnetization, the mean size of the particles was obtained: $15 \mathrm{~nm}$ with a standard deviation, $\sigma$, of $4 \mathrm{~nm}$. The zero field cooling - field cooling (ZFC-FC) curve of the sample was also measured by SQUID magnetometer $(\mathrm{H}=10 \mathrm{Oe})$. From the ZFC-FC curve, the blocking temperature $T_{\mathrm{B}}$ of the water dispersed sample was obtained: $78 \mathrm{~K}$, as calculated from the maximum derivative of the subtraction of ZFC and FC branches over temperature. Clearly, the iron oxide nanoparticle sample is in superparamagnetic regime around and above room temperature.

When applying an AC magnetic field to a sample of magnetic nanoparticles:

$$
H_{\mathrm{AC}}=H_{\mathrm{app}} e^{j \cdot \omega \cdot t}
$$

the sample magnetization is given by:

$$
M(t)=\sum_{n=1}^{\infty} M_{\mathrm{n}} e^{j \cdot \omega \cdot n \cdot t}
$$

where the $M_{\mathrm{n}}$ coefficients are complex numbers that depend on magnetic field intensity $\left(H_{\text {app }}\right)$ and frequency $(\omega)$ :

$$
M_{\mathrm{n}}=\left|M_{\mathrm{n}}\right| e^{j \cdot \varphi_{\mathrm{n}}}
$$

$M_{\mathrm{n}}$ is defined as the $\mathrm{n}^{\text {th }}$ order harmonic component of the magnetization with their corresponding magnitudes $\left|M_{\mathrm{n}}\right|$ and phases $\varphi_{\mathrm{n}}$. The first term, $n=1$, is called the fundamental harmonic and the coefficient of proportionality between the field and the magnetization 
This document is the Accepted Manuscript version of a Published Work that appeared in final form in Appl. Phys. Lett. 107, 123103 (2015) @ AIP Publishing LLC (American Institute of Physics, USA) after peer review and technical editing by the publisher. To access the final edited and published work see http://dx.doi.org/10.1063/1.4931457

defines the usual magnetic susceptibility. Terms of $n \geq 2$, correspond to the high order harmonics. Usually, the magnitude of the harmonics decrease with their order $(n)$ and only the ones below a certain order are considered. Because the dynamic magnetization is antisymmetric versus the applied magnetic field $\left(H_{A C}\right)$, the even order harmonics $(n=2,4,6, \ldots)$ are null.

In order to obtain the spectrum of the MNP sample magnetization, first the AC hysteresis loops or dynamic magnetization, $M(t)$, were measured by the lab-made AC magnetometer descried in an earlier work ${ }^{20}$. Afterward, the Fast Fourier Transform (FFT) of the $M(t)$ signal was performed in order to obtain the complex harmonics $M_{\mathrm{n}}$ with their corresponding magnitudes $\left|M_{\mathrm{n}}\right|$ and phases $\varphi_{\mathrm{n}}$ (see equation (3)). The whole process takes around 0.5 seconds. To measure the thermal dependence of the harmonics, the temperature of the sample was varied in the biological range between $30^{\circ} \mathrm{C}$ and $50{ }^{\circ} \mathrm{C}$ and the values of $M_{\mathrm{n}}$ from $n=1$ to $n=7$ were measured continuously. The actual temperature of the sample was measured by an optical fiber thermometer with the probe in direct contact with the colloidal suspension.

\section{RESULTS}

In this scope, the dynamic magnetization of the prepared nanoparticle sample was measured at different frequencies $(75 \mathrm{kHz}, 302 \mathrm{kHz}, 676 \mathrm{kHz}$ and $1030 \mathrm{kHz})$ for different applied magnetic field intensities. From the dynamic magnetization, $\mathrm{M}(\mathrm{t})$, the different harmonic components (first 7 harmonics) were calculated by FFT. In figure 1 the magnitude $\left|M_{\mathrm{n}}\right|$ of different harmonics are displayed for different applied magnetic field intensities. As expected, only odd harmonics $\left(1^{\text {st }}, 3^{\text {rd }}, 5^{\text {th }}, 7^{\text {th }}, \ldots\right)$ are present since the dynamic magnetization is antisymmetric. In addition, the phases and magnitudes of all the harmonics vary with field intensity: above $5 \mathrm{kA} \cdot \mathrm{m}^{-1}$ field intensity, the high order harmonics are large enough to be measured by the used AC magnetometer, otherwise the signal is too noisy.

The AC hysteresis loop area and $S A R$ values vary with temperature as reported in the literature $^{21,22,26}$. This thermal dependence is the direct result of the variation with temperature of the phase between magnetization $M$ and applied magnetic field $H$. Hence, one can deduce that the harmonic phases of magnetization signal must vary with temperature as well. Therefore, the harmonic spectrum of the magnetization of water dispersed maghemite 
This document is the Accepted Manuscript version of a Published Work that appeared in final form in Appl. Phys. Lett. 107, 123103 (2015) () AIP Publishing LLC (American Institute of Physics, USA) after peer review and technical editing by the publisher. To access the final edited and published work see http://dx.doi.org/10.1063/1.4931457
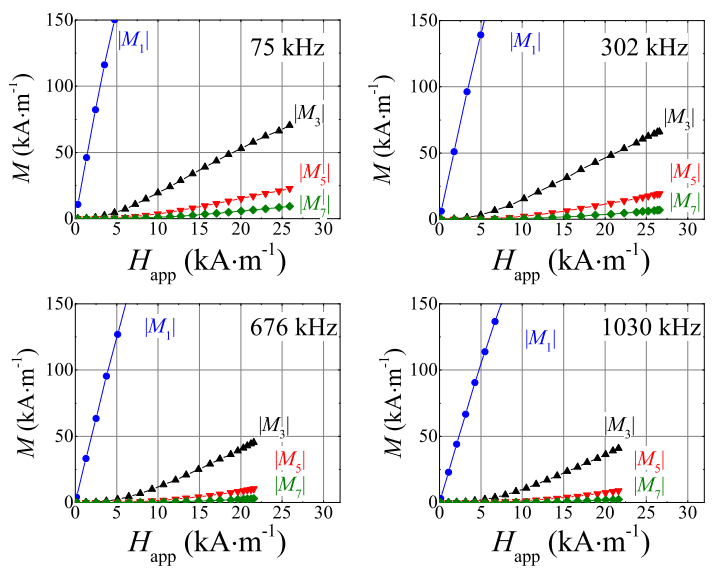

FIG. 1. The magnitude of different harmonics $\left(1^{\text {st }}, 3^{\text {rd }}, 5^{\text {th }}\right.$ and $\left.7^{\text {th }}\right)$ for different applied magnetic field intensities at each frequency measured at $25^{\circ} \mathrm{C}$. The high order harmonics start to rise above $5 \mathrm{kA} \cdot \mathrm{m}^{-1}$.

sample was measured when varying temperature from 30 to $50^{\circ} \mathrm{C}$ at different field frequencies $(75,302,676$ and $1030 \mathrm{kHz})$ and intensities $\left(5,10,20\right.$ and $\left.25 \mathrm{kA} \cdot \mathrm{m}^{-1}\right)$. Figure 2 shows the so obtained results at 10 and $20 \mathrm{kA} \cdot \mathrm{m}^{-1}$ field intensities and for different field frequencies.
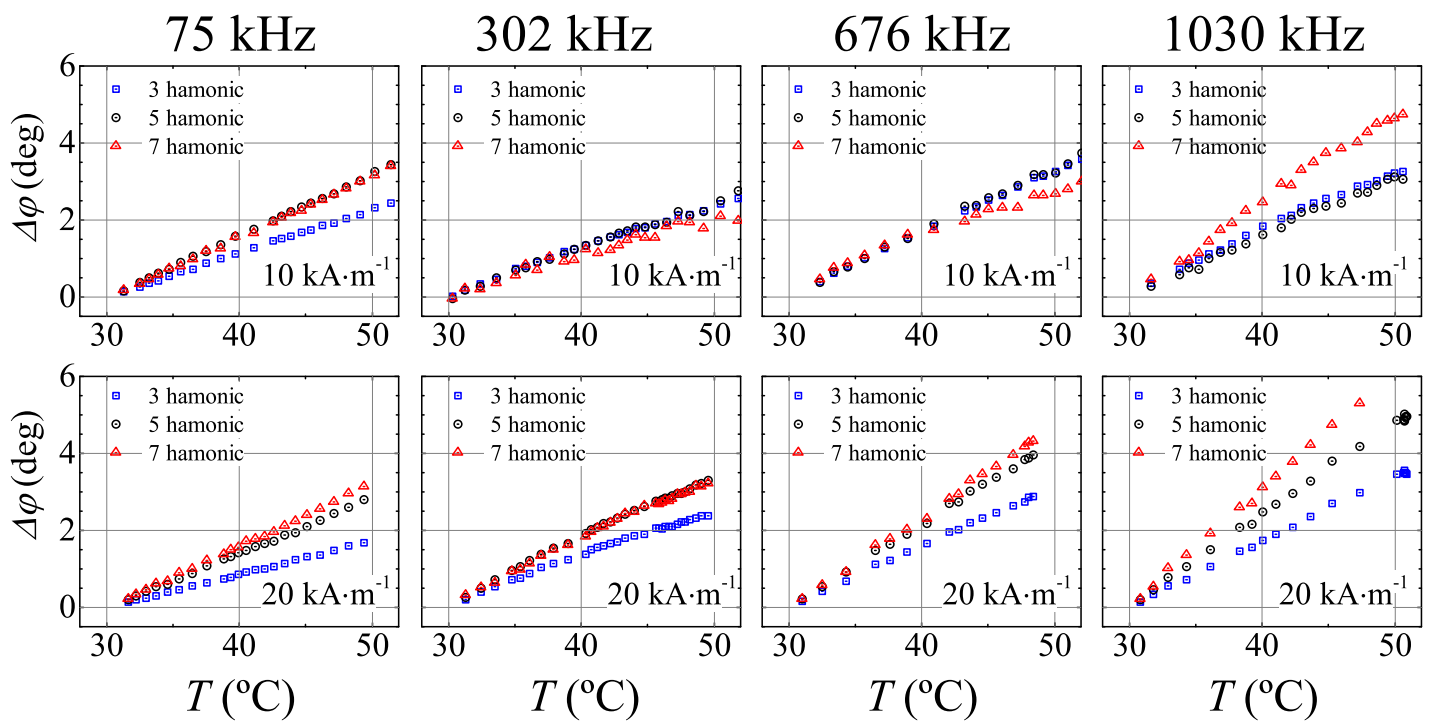

FIG. 2. Variations of harmonic phases $\Delta \varphi$ (relative to the phase at $30^{\circ} \mathrm{C}$ ) with temperature.

As shown in figure 2, the phase increases with rising temperature in almost linear manner for all the harmonics at $10 \mathrm{kA} \cdot \mathrm{m}^{-1}$ and $20 \mathrm{kA} \cdot \mathrm{m}^{-1}$ applied magnetic field intensities. At $5 \mathrm{kA} \cdot \mathrm{m}^{-1}$ and $25 \mathrm{kA} \cdot \mathrm{m}^{-1}$ field intensities (not shown in figure 2) the harmonic phases exhibit 
This document is the Accepted Manuscript version of a Published Work that appeared in final form in Appl. Phys. Lett. 107, 123103 (2015) () AIP Publishing LLC (American Institute of Physics, USA) after peer review and technical editing by the publisher. To access the final edited and published work see http://dx.doi.org/10.1063/1.4931457

the same behavior, that is, their phase also increases with raising temperature in almost linear manner. In this scope, we propose here the measurement of the harmonic phases as a non-invasive method to obtain the sample temperature which depends on the intrinsic properties of the nanoparticles. In this way, the temperature would be obtained via the previously measured temperature dependence of harmonic phase (see figure 2).

In order to obtain the temperature from the harmonic phases, it is necessary to fit the measured data by a phenomenological expression. At a first approach, the measured phase shifts can be fitted to a linear function. To estimate the fitting quality, the $R$ squared coefficients were calculated (see equation (4)). Note that these $R^{2}$ coefficients are 1 for a perfect fit and zero for a null correlation. In table I, the calculated $R^{2}$ coefficients are written for different frequencies, intensities and harmonic orders.

$$
R^{2}=1-\frac{\sum_{i}\left(y_{i}-f_{i}\right)^{2}}{\sum_{i}\left(y_{i}-\bar{y}\right)^{2}}
$$

\begin{tabular}{ccccc}
\hline \hline $\begin{array}{c}\text { Freq. } \\
(\mathrm{kHz})\end{array}$ & $\begin{array}{c}\text { Intensity } \\
\mathrm{kA} \cdot \mathrm{m}^{-1}\end{array}$ & $3^{\text {rd }}$ & $\begin{array}{c}\text { Linear fit } \\
5^{\text {th }}\end{array}$ & $7^{\text {th }}$ \\
\hline \multirow{3}{*}{$\mathbf{7 5}$} & 5 & 0.99457 & 0.99485 & 0.99479 \\
& 10 & 0.99924 & 0.99952 & 0.99888 \\
& 20 & 0.99934 & 0.99864 & 0.99866 \\
& 25 & 0.98718 & 0.98889 & 0.98796 \\
$\mathbf{3 0 2}$ & 5 & 0.99932 & 0.93364 & 0.00148 \\
& 10 & 0.99381 & 0.99445 & 0.97488 \\
& 20 & 0.99389 & 0.99531 & 0.99475 \\
& 25 & 0.99457 & 0.99485 & 0.99479 \\
$\mathbf{6 7 6}$ & 5 & 0.99714 & 0.75294 & 0.04553 \\
& 10 & 0.99908 & 0.99654 & 0.98639 \\
& 20 & 0.99888 & 0.99872 & 0.99808 \\
$\mathbf{1 0 3 0}$ & 10 & 0.99788 & 0.78314 & 0.79162 \\
& 20 & 0.99918 & 0.99423 & 0.93086 \\
Averaged & & 0.9989 & 0.99892 & 0.99882 \\
\hline \hline
\end{tabular}

TABLE I. $R$ squared coefficients of the linear fittings of the measured phase versus temperature curves. Each column represents different harmonic order $\left(3^{\text {rd }}, 5^{\text {th }}\right.$ and $\left.7^{\text {th }}\right)$. The blue color indicates a $R$ squared coefficient between 0.999 and 1, the green color a coefficient between $0.990 \quad 0.999$ and the red ones indicates a coefficient smaller than 0.990 .

As it can be appreciated in table I, the errors increase with the harmonic order: for the 
This document is the Accepted Manuscript version of a Published Work that appeared in final form in Appl. Phys. Lett. 107, 123103 (2015) ( AIP Publishing LLC (American Institute of Physics, USA) after peer review and technical editing by the publisher. To access the final edited and published work see http://dx.doi.org/10.1063/1.4931457

$3^{\text {rd }}$ harmonic, $R^{2}$ coefficient values are higher. This difference is more noticeable at very small applied magnetic field intensities (see table I at $5 \mathrm{kA} \cdot \mathrm{m}^{-1}$ ). Clearly, this fact is an instrumental (statistical) error caused by too low magnitudes of higher order harmonics, compared to the fundamental harmonic magnitude (low signal-to-noise ratio, see figure 1). On the other hand, the error increases at $25 \mathrm{kA} \cdot \mathrm{m}^{-1}$. This error can be induced by the power amplifier that feeds our particular resonant circuit and generates the magnetic field ${ }^{20}$. At high field intensities, the amplifier works near its own saturation and tends to add harmonics to the output signal. Hence, high order harmonics appear in the applied magnetic field, $H(t)$, and although their magnitude is very small, they can add errors to the measurements.

Considering the fittings with higher squared $R$ values, temperature measurements and the control of temperature can be well performed by using the $3^{\text {rd }}$ harmonic. The temperature setup scheme in figure 3 can be followed to control the temperature of a nanoparticle sample. The dynamic magnetization of MNP suspension is measured by pick-up coils and then FFT is performed to obtain the $3^{\text {rd }}$ harmonic phase. Using the previously measured data, the phases can be converted into temperatures and control the intensity of the applied magnetic field $\left(H_{\text {app }}\right)$ to set the sample temperature at $T$ through a proportional integral differential (PID) feedback loop.

Finally, the following experiment was made in order to check the sensitivity of the proposed thermometric method: an $\mathrm{AC}$ magnetic field of $302 \mathrm{kHz}$ was applied to the tested magnetic nanoparticle sample by means of the used electromagnetic applicator. The sample holder consisted of a $2 \mathrm{~cm}$ length and $1 \mathrm{~cm}$ diameter cylindrical vessel. While the temperature was rising, the $3^{\text {rd }}$ order harmonic phases were measured and recorded every 1 second by means of the used AC magnetometer. Then, the harmonic phases were converted to temperature by means of the previous measurements and linear regressions (see figure 2 and table I). The so obtained temperatures were compared with the ones measured by the optical fiber thermometer (OpSens, Québec City, Canada) whose sensor tip was in direct contact with the sample. Figure 4 shows the temperature evolution curves measured by both methods. As it can be appreciated, the temperature obtained by the proposed method is in good agreement with the one measured by the commercial thermometer. The calculated root-mean-square error (RMSE) is 0.39 and $0.34{ }^{\circ} \mathrm{C}$ for $10 \mathrm{kA} \cdot \mathrm{m}^{-1}$ and $20 \mathrm{kA} \cdot \mathrm{m}^{-1}$ respectively. 
This document is the Accepted Manuscript version of a Published Work that appeared in final form in Appl. Phys. Lett. 107, 123103 (2015) @ AIP Publishing LLC (American Institute of Physics, USA) after peer review and technical editing by the publisher. To access the final edited and published work see http://dx.doi.org/10.1063/1.4931457

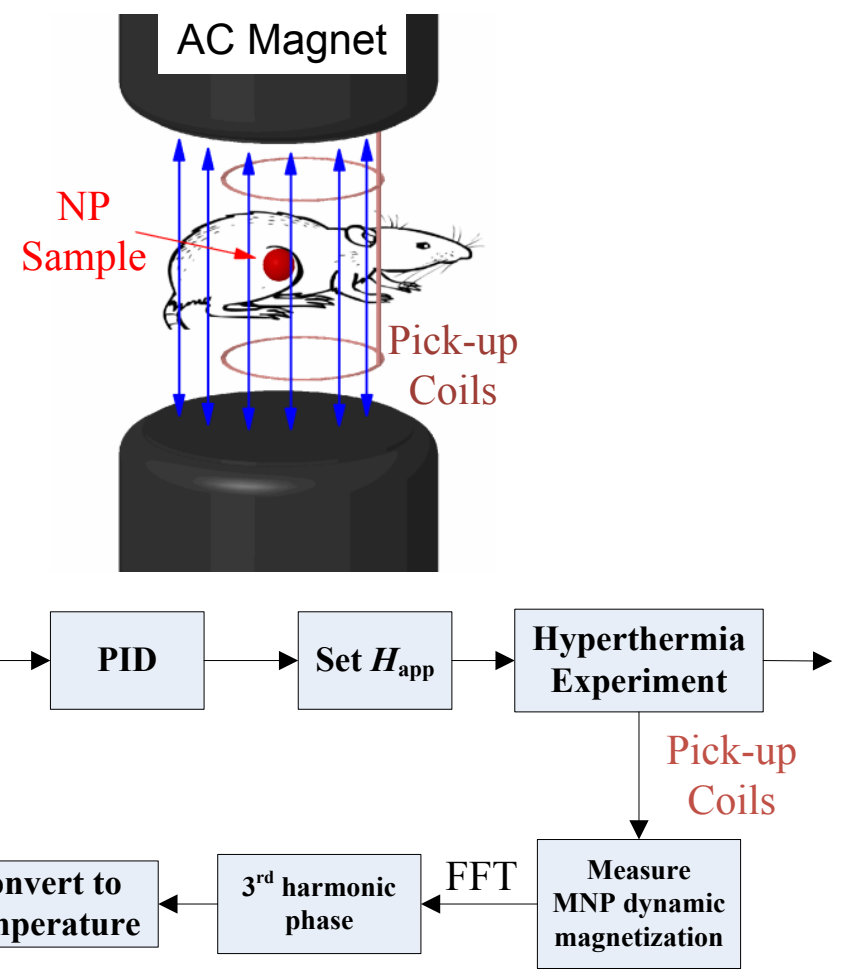

FIG. 3. One possible temperature control scheme for magnetic hyperthermia experiments.
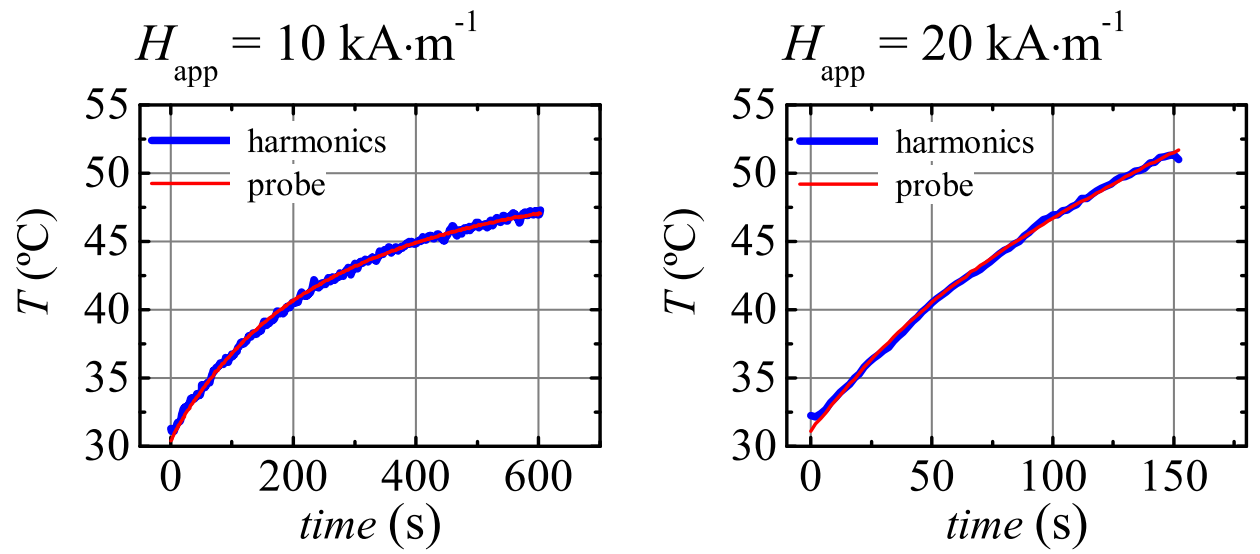

FIG. 4. Temperature evolution measured with the optic fiber thermometer and the temperature obtained from the harmonic phases. The calculated root mean square error, $\sqrt{\left\langle\left(T_{\text {harmonics }}-T_{\text {probe }}\right)^{2}\right\rangle}$, is 0.39 and $0.34{ }^{\circ} \mathrm{C}$ at $10 \mathrm{kA} \cdot m^{-1}$ and $20 \mathrm{kA} \cdot \mathrm{m}^{-1}$ respectively.

\section{CONCLUSIONS}

The thermal dependence of the high order harmonics of a water dispersed maghemite nanoparticle sample was studied. From measured data, it was observed that the high order 
This document is the Accepted Manuscript version of a Published Work that appeared in final form in Appl. Phys. Lett. 107, 123103 (2015) @ AIP Publishing LLC (American Institute of Physics, USA) after peer review and technical editing by the publisher. To access the final edited and published work see http://dx.doi.org/10.1063/1.4931457

harmonic phases $\left(3^{\text {rd }}, 5^{\text {th }}\right.$ and $\left.7^{\text {th }}\right)$ increase with temperature in an almost linear way. The phase increment ranges between 1 and 3.5 degrees when sample temperature varies from 30 to $50^{\circ} \mathrm{C}$, which is easily measured.

We propose here the measurement of high order harmonic phase as a non-invasive method to obtain the temperature of a magnetic nanoparticle sample. This method has the potential to be only dependent on the intrinsic properties of the magnetic nanoparticles. Therefore once the method is calibrated (i.e. the linear regression slopes of $3^{\text {rd }}$ harmonic phases versus temperature) for a given set of magnetic nanoparticles, it allows acquiring and controlling the temperature of the tissues at a constant predetermined value (e.g. $43^{\circ} \mathrm{C}$ ) during magnetic hyperthermia therapy. We propose the $3^{\text {rd }}$ harmonic as a good system from which the temperature of a nanoparticle sample can be obtained and controlled.

The use of higher than fundamental harmonics to obtain the temperature has many potential advantages. First, the paramagnetic and diamagnetic signals of the sample are removed, since they are linear with applied field intensity and they are only present in the fundamental harmonic. For the same reason, the error from an uncompensated pickup coil ${ }^{20}$ vanishes as well. Secondly, these harmonics are measured in magnetic particle imaging technique, although at somewhat lower frequency, typically in $25-100 \mathrm{kHz}$ range. But the method proposed here is still applicable (see the $75 \mathrm{kHz}$ line in table I). Therefore, this non-invasive thermometry method specific to magnetized volumes could be combined with MPI to obtain the spatial distribution of particles and their temperature inside and around tumor (everywhere magnetic NPs are localized). Besides, due to the relatively low frequencies (lower than for MRI) involved with magnetic hyperthermia at which the body is transparent, the magnetization harmonics and thus temperature of nanoparticles located in deep tissues could be recorded. The method could be also implemented to study the heat transfer between nanoparticles and the surrounding media or other thermal phenomena related to magnetic nanoparticles.

\section{ACKNOWLEDGMENTS}

The authors thank the European COST action TD1402 "Multifunctional Nanoparticles for Magnetic Hyperthermia and Indirect Radiation Therapy" (RADIOMAG). This work has been financed by the Basque Government under grant IT-443-10. 
This document is the Accepted Manuscript version of a Published Work that appeared in final form in Appl. Phys. Lett. 107, 123103 (2015) @ AIP Publishing LLC (American Institute of Physics, USA) after peer review and technical editing by the publisher. To access the final edited and published work see http://dx.doi.org/10.1063/1.4931457

\section{REFERENCES}

${ }^{1}$ R. Hergt, S. Dutz, R. Müller, and M. Zeisberger, "Magnetic particle hyperthermia: nanoparticle magnetism and materials development for cancer therapy," Journal of Physics: Condensed Matter, vol. 18, no. 38, pp. S2919-S2934, 2006.

${ }^{2} \mathrm{~S}$. Dutz and R. Hergt, "Magnetic nanoparticle heating and heat transfer on a microscale: Basic principles, realities and physical limitations of hyperthermia for tumour therapy," International Journal of Hyperthermia, vol. 29, no. 8, pp. 790-800, 2013.

${ }^{3}$ S. Laurent, D. Forge, M. Port, A. Roch, C. Robic, L. V. Elst, and R. N. Muller, "Magnetic iron oxide nanoparticles: Synthesis, stabilization, vectorization, physicochemical characterizations, and biological applications," Chemical Reviews, vol. 110, no. 4, p. 2574, 2010. ${ }^{4}$ Q. Pankhurst, J. Connolly, S. Jones, and J. Dobson, "Applications of magnetic nanoparticles in biomedicine," Journal of Physics D - Applied physics, vol. 36, no. 13, pp. R167R181, 2003.

${ }^{5}$ B. Gleich and J. Weizenecker, "Tomographic imaging using the nonlinear response of magnetic particles," Nature, vol. 435, no. 7046, pp. 1214-1217, 2005.

${ }^{6}$ J. Rahmer, A. Halkola, B. Gleich, I. Schmale, and J. Borgert, "First experimental evidence of the feasibility of multi-color magnetic particle imaging," Physics in Medicine and Biology, vol. 60, no. 5, pp. 1775-1791, 2015.

${ }^{7}$ S. Dutz and R. Hergt, "Magnetic particle hyperthermia - a promising tumour therapy?," Nanotechnology, vol. 25, no. 45, p. 452001, 2014.

${ }^{8}$ B. Quesson, J. A. de Zwart, and C. T. Moonen, "Magnetic resonance temperature imaging for guidance of thermotherapy," Journal of Magnetic Resonance Imaging, vol. 12, no. 4, pp. 525-533, 2000 .

${ }^{9}$ R. Epherre, E. Duguet, S. Mornet, E. Pollert, S. Louguet, S. Lecommandoux, C. Schatz, and G. Goglio, "Manganite perovskite nanoparticles for self-controlled magnetic fluid hyperthermia: about the suitability of an aqueous combustion synthesis route," Journal of Materials Chemistry, vol. 21, no. 12, pp. 4393-4401, 2011.

${ }^{10}$ M. Barati, C. Selomulya, K. Sandeman, and K. Suzuki, "Extraordinary induction heating effect near the first order Curie transition," Applied Physics Letters, vol. 105, p. 162412, 2014.

${ }^{11}$ R. Piñol, C. D. S. Brites, R. Bustamante, A. Martínez, N. J. O. Silva, J. L. L. Murillo, 
R. Cases, J. Carrey, C. Estepa, C. Sosa, F. Palacio, L. D. Carlos, and A. Millán, "Joining Time-Resolved Thermometry and Magnetic-Induced Heating in a Single Nanoparticle Unveils Intriguing Thermal Properties," ACS Nano, vol. 9, no. 3, pp. 3134-3142, 2015.

${ }^{12}$ A. Hannecart, D. Stanicki, L. Vander Elst, R. N. Muller, S. Lecommandoux, J. Thevenot, C. Bonduelle, A. Trotier, P. Massot, S. Miraux, O. Sandre, and S. Laurent, "Nanothermometers with thermo-sensitive polymer grafted USPIOs behaving as positive contrast agents in low-field MRI," Nanoscale, vol. 7, no. 8, pp. 3754-3767, 2015.

${ }^{13}$ J. B. Weaver, A. M. Rauwerdink, and E. W. Hansen, "Magnetic nanoparticle temperature estimation," Medical Physics, vol. 36, no. 5, pp. 1822-1829, 2009.

${ }^{14} \mathrm{M}$. Ma, Y. Wu, J. Zhou, Y. Sun, Y. Zhang, and N. Gu, "Size dependence of specific power absorption of $\mathrm{Fe}_{3} \mathrm{O}_{4}$ particles in $\mathrm{AC}$ magnetic field," Journal of Magnetism and Magnetic Materials, vol. 268, pp. 33-39, 2004.

${ }^{15}$ J.-P. Fortin, C. Wilhelm, J. Servais, C. Mánager, J.-C. Bacri, and F. Gazeau, "Size-sorted anionic iron oxide nanomagnets as colloidal mediators for magnetic hyperthermia," Journal of the American Chemical Society, vol. 129, no. 9, pp. 2628-2635, 2007.

${ }^{16}$ E. Kita, S. Hashimoto, T. Kayano, M. Minagawa, H. Yanagihara, M. Kishimoto, K. Yamada, T. Oda, N. Ohkohchi, T. Takagi, T. Kanamori, Y. Ikehata, and I. Nagano, "Heating characteristics of ferromagnetic iron oxide nanoparticles for magnetic hyperthermia," Journal of Applied Physics, vol. 107, no. 9, p. 09B321, 2010.

${ }^{17}$ S. Huang, S.-Y. Wang, A. Gupta, D.-A. Borca-Tasciuc, and S. J. Salon, "On the measurement technique for specific absorption rate of nanoparticles in an alternating electromagnetic field," Measurement Science E3 Technology, vol. 23, no. 3, p. 035701, 2012.

${ }^{18}$ S.-Y. Wang, S. Huang, and D.-A. Borca-Tasciuc, "Potential sources of errors in measuring and evaluating the specific loss power of magnetic nanoparticles in an alternating magnetic field," IEEE Transactions on Magnetics, vol. 49, no. 1, pp. 255-262, 2013.

${ }^{19}$ V. Connord, B. Mehdaoui, R. Tan, J. Carrey, and M. Respaud, "An air-cooled Litz wire coil for measuring the high frequency hysteresis loops of magnetic samples - A useful setup for magnetic hyperthermia applications," Review of Scientific Instruments, vol. 85, no. 9, p. 093904, 2014.

${ }^{20}$ E. Garaio, J. Collantes, F. Plazaola, J. Garcia, and I. Castellanos-Rubio, "A multifrequency electromagnetic applicator with an integrated AC magnetometer for magnetic hyperthermia experiments," Measurement Science and Technology, vol. 25, p. 115702, 2014. 
This document is the Accepted Manuscript version of a Published Work that appeared in final form in Appl. Phys. Lett. 107, 123103 (2015) () AIP Publishing LLC (American Institute of Physics, USA) after peer review and technical editing by the publisher. To access the final edited and published work see http://dx.doi.org/10.1063/1.4931457

${ }^{21}$ R. Regmi, A. Naik, J. S. Thakur, P. P. Vaishnava, and G. Lawes, "Temperature dependent dissipation in magnetic nanoparticles," Journal of Applied Physics, vol. 115, no. 17, p. 17B301, 2014.

${ }^{22}$ E. Garaio, O. Sandre, J.-M. Collantes, J. A. Garcia, S. Mornet, and F. Plazaola, "Specific absorption rate dependence on temperature in magnetic field hyperthermia measured by dynamic hysteresis losses (ac magnetometry)," Nanotechnology, vol. 26, no. 1, p. 015704, 2015 .

${ }^{23}$ E. Garaio, J. Collantes, J. Garcia, F. Plazaola, S. Mornet, F. Couillaud, and O. Sandre, "A wide-frequency range ac magnetometer to measure the specific absorption rate in nanoparticles for magnetic hyperthermia," Journal of Magnetism and Magnetic Materials, vol. 368, pp. 432-437, 2014.

${ }^{24}$ R. Massart, E. Dubois, V. Cabuil, and E. Hasmonay, "Preparation and properties of monodisperse magnetic fluids," Journal of Magnetism and Magnetic Materials, vol. 149, pp. 1-5, 1995.

${ }^{25}$ G. Salas, C. Casado, F. J. Teran, R. Miranda, C. J. Serna, and M. Puerto Morales, "Controlled synthesis of uniform magnetite nanocrystals with high-quality properties for biomedical applications," Journal of Materials Chemistry, vol. 22, pp. 21065-21075, 2012.

${ }^{26}$ M. Beković, M. Trlep, M. Jesenik, V. Goričan, and A. Hamler, "An experimental study of magnetic-field and temperature dependence on magnetic fluid's heating power," Journal of Magnetism and Magnetic Materials, vol. 331, pp. 264-268, 2013. 
$75 \mathrm{kHz}$
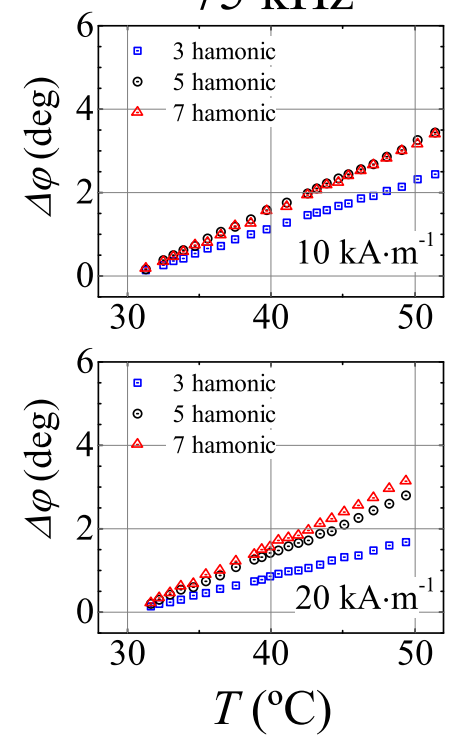

$302 \mathrm{kHz}$
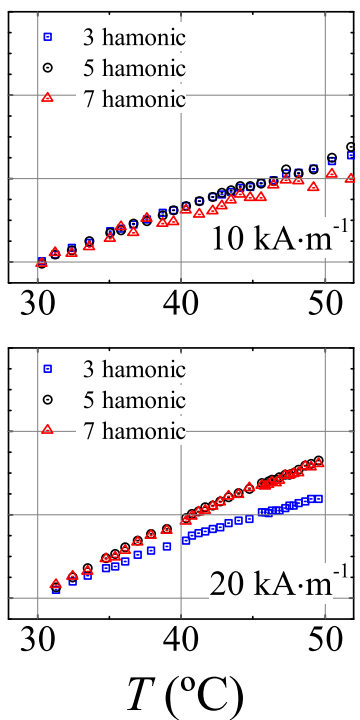

$676 \mathrm{kHz}$
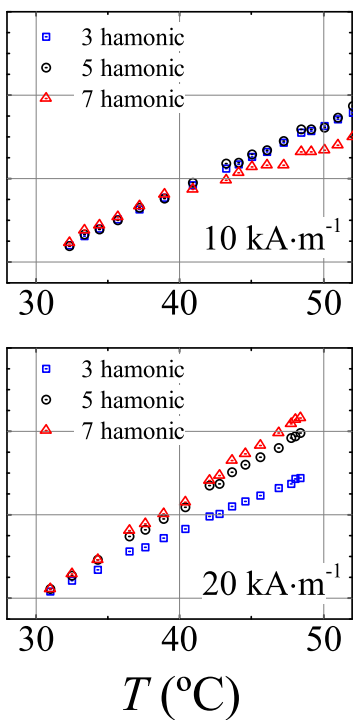

$1030 \mathrm{kHz}$
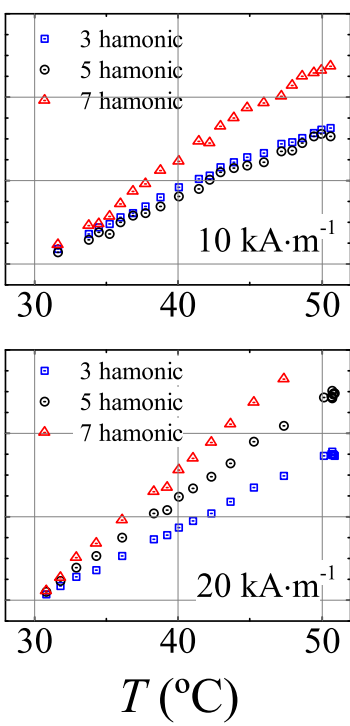

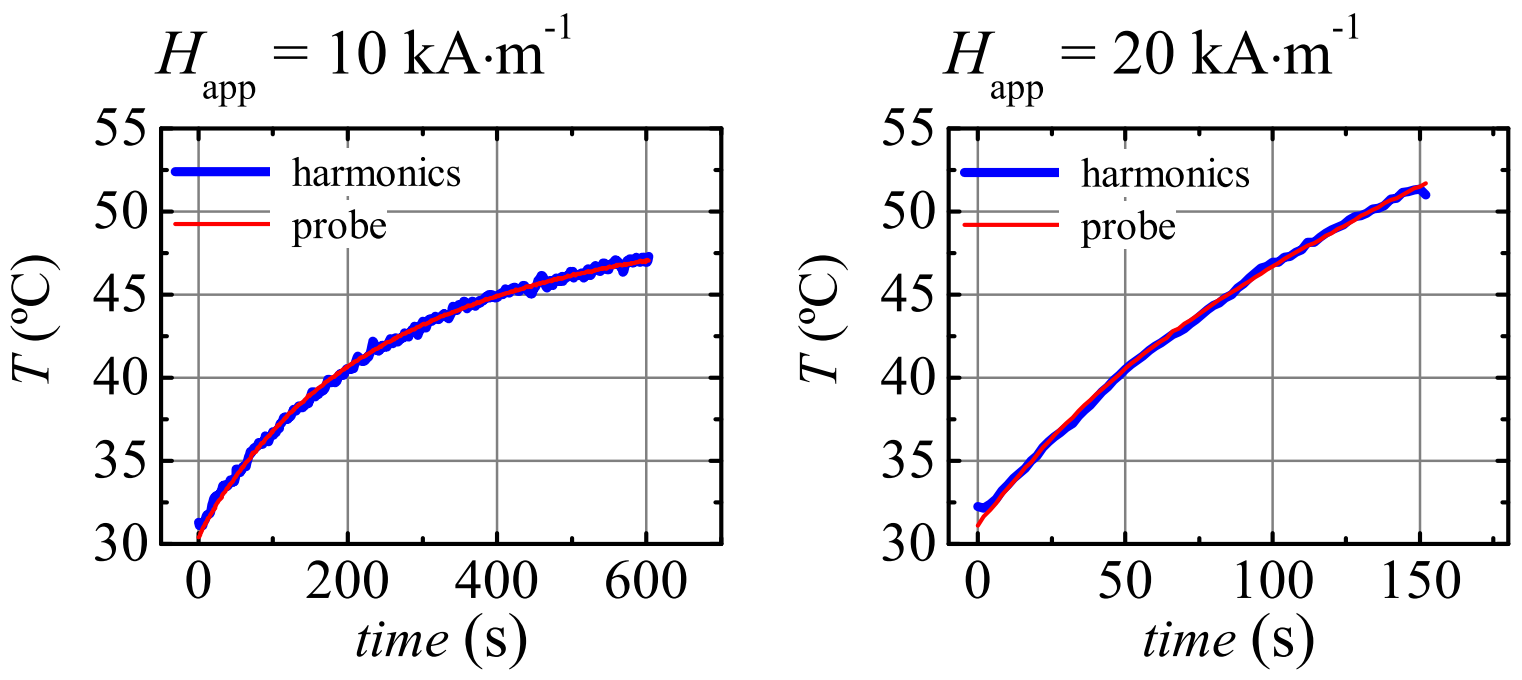
This document is the Accepted Manuscript version of a Published Work that appeared in final form in Appl. Phys. Lett. 107, 123103 (2015) () AIP Publishing LLC (American Institute of Physics, USA) after peer review and technical editing by the publisher. To access the final edited and published work see http://dx.doi.org/10.1063/1.4931457

\section{Harmonic phases of the nanoparticle magnetization: an intrinsic temperature probe}

Eneko Garaio ${ }^{1}$, Juan-Mari Collantes ${ }^{1}$, Jose Angel Garcia ${ }^{2,3}$, Fernando Plazaola ${ }^{1}$ and Olivier Sandre ${ }^{4}$

\footnotetext{
${ }^{1}$ Elektrizitatea eta Elektronika Saila, UPV/EHU, 644.48080 Bilbao. Spain ${ }^{2}$ Fisika Aplikatua II Saila, UPV/EHU, 644.48080 Bilbao. Spain

${ }^{3}$ BC Materials (Basque Center for Materials, Application and Nanostructures) 48040 Leioa. Spain

${ }^{4}$ Laboratoire de Chimie des Polymères Organiques, UMR 5629 CNRS/Université de Bordeaux, Bordeaux. France
}

\section{Supplementary Information:}
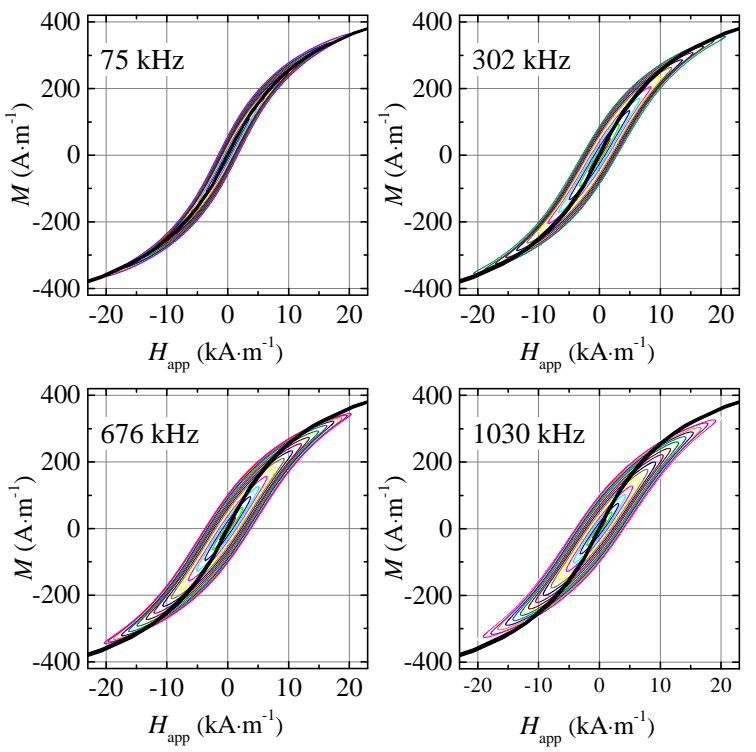

Figure S1: AC hysteresis cycles of the magnetic nanoparticle sample from which the harmonics were obtained. The cycles were measured at different field intensities (up to $20 \mathrm{kA} \cdot \mathrm{m}^{-1}$ ) and frequencies (see graphs). Black lines represent the DC magnetization measured by VSM. Clearly, the loops get broader as the frequency increases. 